\title{
Androgenic activity of effluent from forty-five municipal waste water treatment plants in Victoria, Australia
}

\author{
G. Allinson ${ }^{1}$, M. Allinson ${ }^{1}$, F. Shiraishi ${ }^{2}$, S. A. Salzman ${ }^{3}$, \\ J. H. Myers ${ }^{4}$, K. M. Hermon ${ }^{1} \&$ T. Theodoropoulos ${ }^{1}$ \\ ${ }^{I}$ Future Farming Systems Research, Department of Primary Industries, \\ Queenscliff, Victoria, Australia \\ ${ }^{2}$ Exposure Assessment Research Section National Institute for \\ Environmental Studies, Tsukuba, Ibaraki 305-8506, Japan \\ ${ }^{3}$ School of Information Systems, Deakin University, Warrnambool, \\ Victoria, Australia \\ ${ }^{4}$ School of Biological Sciences, Monash University, Victoria, Australia
}

\begin{abstract}
It is well known that waste water treatment plant (WWTP) effluents are estrogenic. There has been much less consideration of the androgenic activity of WWTP effluents. To partly address the shortage of information on androgens in Australian WWTP effluents, in August 2006, and again in 2007, we collected discharges from up to 45 Victorian WWTPs ( $25 \%$ of all WWTPs in Victoria), grouped by treatment process, i.e. activated sludge, extended aeration, and lagoon based treatment, and measured the total estrogenic, androgenic, retinoic acid, and aromatic hydrocarbon hydrogenase activity of the effluents using a hybrid yeast bioassay. This paper will concentrate on the androgenic activity and male hormone concentrations. None of the WWTP effluents produced a response in the yeast assay. However, that does not mean there are no androgens in the effluents. The ELISA testing suggested that there are low levels of testosterone and androstenedione in the WWTP discharges (typically less than 5 and $10 \mathrm{ng} / \mathrm{L}$, respectively). The lack of response in the androgen assay may reflect lack of test sensitivity, rather than lack of androgenic activity, per se. The low concentrations of testosterone and androstenedione found in our Victorian WWTP effluents are broadly consistent with the few observations made elsewhere in Australia. Also, it is not just the big cities that produces hormonally active WWTP effluent, but also smaller communities. Indeed, some small community effluent contains more testosterone/androstenedione than that of large cities.
\end{abstract}

Keywords: androgenic activity, testosterone, androstenedione, waste water treatment plant effluent. 


\section{Introduction}

The last several decades has seen concerns raised that a range of chemicals found in municipal waste water treatment plant (WWTP) discharges can cause adverse environmental impacts. More recently, the occurrence of endocrine disrupting chemicals (EDCs) in WWTP discharges and their impact on aquatic wildlife has generated a significant amount of scientific and public interest since the publication of the book Our Stolen Future [1]. Since then, substantial evidence has emerged that many chemicals induce hormone-like effects in wildlife and humans at the concentrations observed in the environment (concentrations much lower than those used in toxicity tests designed to see if the chemicals cause cancer) [2].

The effluent from municipal WWTPs is often considered the source of much of the EDC input into aquatic environments. Some of the most commonly studied compounds found in WWTP discharges that show hormonal activity are the natural and synthetic estrogens, such as $17 \beta$-estradiol and $17 \alpha$-ethynyl-estradiol.

However, compared to the estrogens, there is still very little information on the overall level of androgenic activity and concentrations of specific hormonal compounds WWTP discharges, including recycled water in Australia. The information that is available in Australia is both very limited and variable, with reports of both very high and low concentrations in Queensland [3,4]. This discrepancy across the country is of both scientific and practical interest to water managers.

There have been no previous reports of androgen concentrations in Victorian WWTP effluents, and so following extensive consultation with stakeholder groups (e.g. government, water authorities, waterway managers) this study was initiated to in part address this knowledge gap. Specifically, this study measured the hormonal activity and concentration of several specific natural hormones (including the androgens testosterone and androstenedione reported herein) in the effluents of forty-five WWTPs across Victoria. The WWTPs were grouped by treatment type (to assess if there was any simple correlation between treatment technology and hormonal activity) and location (to address the hypothesis that regional differences in reported hormonal activity are a function of local ambient temperatures), in the Victorian winter and summer of 2006 / 07 (to assess seasonal changes in hormonal activity).

\section{Materials and methods}

\subsection{Sample collection}

Basic information on WWTPs (e.g. treatment type, location), was obtained from published information on water business websites and in reports, and/or directly from the water authorities. Using this information, a list of 46 WWTPs to be sampled was compiled. Samples were collected with the assistance and agreement of the WWTP operators on condition that they are not identified when publishing results. Hence, hereafter only the treatment group and broad location of the WWTPs (i.e. activated sludge-based plants, north or south of the state) will be discussed. The study's groups comprised three broad treatment types 
further sub-divided by location (with north $(\mathrm{N})$ and south $(\mathrm{S})$ defined as being north or south of the Great Dividing Range), namely: activated sludge-based plants (AS: S, 13; N, 5), activated sludge (extended aeration)-based plants (AS(EA): $S=7 ; N=4)$, and lagoon-based plants ( $\mathrm{L}: \mathrm{S}=8 ; \mathrm{N}=8$ ).

Two surveys of the intended 46 WWTPs were conducted: Phase 1 (Winter 2006) in the three weeks between August 14 and 31, 2006; and Phase 2 (Summer 2007) in the four weeks from February 12 - March 7, 2007. Samples could not be obtained from one WWTP in the Winter 2006 survey for logistical reasons, and was removed from the Summer 2007 survey. Samples could not be obtained from five WWTPs in the Summer 2007 survey, also for logistical reasons. In this case, however, the Winter 2006 data has been retained in statistical comparisons.

Water samples were collected as 'grab,' or spot samples, from each facility at the point at which effluent enters the environment, either as recycled water or direct discharge to the receiving water. In Winter 2006, 1.5-2.5L of water was collected, whereas in Summer 2007, 5-6L of water was collected (to facilitate additional method development and testing not reported herein). Although for the most part discharges were sampled in the same manner, at times sampling protocols were modified dependent upon on-site conditions. For instance, generally samples were collected by members of the research team, although some samples were collected by plant personnel (for safety reasons or convenience). Samples were directly collected in glass bottles, stored on ice, and then at $4^{\circ} \mathrm{C}$ until processed.

\subsection{Measurement of androgenic activity with yeast two-hybrid assay}

For each WWTP site, a sample (1L) was extracted for the measurement of androgenic activity using a yeast two-hybrid assay. Prior to filtration or extraction, $10 \mathrm{~mL}$ of an acetic acid: water: methanol (1:9:90) buffer solution was added to the sample $(1 \mathrm{~L})$ to ensure an acid $\mathrm{pH}$. Samples were then filtered with $\mathrm{GF} / \mathrm{C}$ filters (Whatman International Ltd, UK) to remove particulate matter. The sample was then passed through a C18 SPE disk (octadecyl C18; Empore; 47 $\mathrm{mm}$; 3M, MN, USA), which had previously been conditioned with sequential washes of methanol $(10 \mathrm{~mL})$, and deionised water (water having a resistivity of at least $18 \mathrm{M} \Omega \mathrm{cm}^{-1}$ produced by passing singly distilled water through a Milli-Q Water Purification System; $20 \mathrm{~mL}$ ). Thereafter, the disks were immediately washed with deionised water $(20 \mathrm{~mL})$, and dried at $35^{\circ} \mathrm{C}$ on a hotplate for approximately 1.5 hours. Each disk was wrapped separately in aluminium foil, labelled, placed inside another labelled plastic bag, and stored at $-4^{\circ} \mathrm{C}$ until transported to Japan for analyte elution and analysis.

Each disk was eluted with methanol $(10 \mathrm{~mL})$ into a screw cap glass tube (Iwaki borosilicate glass; Asahi Techno Glass, Tokyo), and the resulting solution evaporated to dryness with nitrogen, and the residue immediately frozen $\left(-20^{\circ} \mathrm{C}\right)$ until separation the following day. The sample was then subjected to a crude fractionation process to isolate fractions containing non-polar chemicals (e.g. many of the persistent organic pollutants), the steroid hormones, and polar compounds. 
The sample was re-suspended in a mixture of 3:1 hexane: dichloromethane $(1 \mathrm{~mL}$ ), and loaded onto a florisil column (Varian Bond Elut-FL, $500 \mathrm{mg}, 3 \mathrm{~mL}$; CA, USA) which had previously been conditioned with hexane $(2.5 \mathrm{~mL})$. After loading of the sample onto the column, the column was washed twice with a mixture of $3: 1$ hexane : dichloromethane $(2.5 \mathrm{~mL})$. The sample solution passing through the florisil column and the collected washes were combined and designated the $\mathrm{W}$ fraction. Thereafter, the cartridge was washed with a mixture of 1:9 acetone : dichloromethane $(2 \times 2.5 \mathrm{~mL})$. The collected washes were combined and designated the FL fraction. Finally, the cartridge was washed with methanol $(2 \times 2.5 \mathrm{~mL})$, and the collected wash designated the RM fraction. The $\mathrm{W}, \mathrm{FL}$ and RM fractions were evaporated to dryness under nitrogen, and frozen $\left(-20^{\circ} \mathrm{C}\right)$.

Samples and standards were removed from the freezer $1 \mathrm{~h}$ prior to analysis, thawed, and dissolved in dimethyl sulphoxide (DMSO; $100 \mu \mathrm{L}$ ), effectively resulting in 10,000-fold concentration from the original effluent sample. The agonist activities of the treated municipal effluent samples were measured with a yeast two-hybrid assay system using yeast cells (Saccharomyces cerevisiae Y190) into which the human androgen receptor (AR) had been inserted, and adapted to a chemiluminescent reported gene (for $\beta$-galactosidase) method employing a 96 well culture plate [5]. In short, yeast cells were cultured $\left(30^{\circ} \mathrm{C}\right.$, overnight; Sanyo Incubator, Tokyo, Japan) in a modified SD (Sabouraud Dextrose) medium (lacking tryptophan and leucine). The yeast solution cell density was measured (595 nm), and, if necessary, adjusted to $1.75-1.85$ readings for constant cell density by diluting with modified SD medium. Modified SD solution $(60 \mu \mathrm{L})$ was added to each well of the first row of a 96-well culture plate (Sumilon 96F disposable plates; Sumilon Bakelite Co., Tokyo, Japan). Thereafter, 2\% DMSO/modified SD solution $(60 \mu \mathrm{L})$ was automatically added (Nichiryo NSP-7000 Multi-channel Auto Sampling System, Nichiryo Co., Tokyo, Japan) to each well of the 2nd - 8th rows of the plate. Six samples were run on each plate, with aliquots of each sample $(60 \mu \mathrm{L})$, added to two, neighbouring wells of the 1 st row of the plate. An aliquot was removed from each well of row 1, and added to row 2 to dilute 2-fold. This process was then repeated from rows $2-7$. No sample solution from row 7 was added to the 8th row. Thereafter, yeast solution $(60 \mu \mathrm{L})$ was added to all wells, the plate shaken (30s; Taiyo S-2000 Automatic Mixer, Taiyo, Tokyo, Japan) and then incubated $\left(30^{\circ} \mathrm{C}, 4 \mathrm{~h}\right)$.

After incubation, a mixed solution $(80 \mu \mathrm{L})$ for inducing chemiluminescence and for enzymatic digestion $(30 \mu \mathrm{L}$ of Aurora GAL-XE Reaction Buffer containing GalactaLux substrate, MP Biomedicals Inc., CA, USA and $50 \mu \mathrm{L}$ of Zymolyase 20T diluted with $\mathrm{Z}$ buffer (a mixture of $21.5 \mathrm{~g} \mathrm{Na}_{2} \mathrm{HPO}_{4} .12 \mathrm{H}_{2} 0 ; 6.2 \mathrm{~g}$ $\mathrm{Na}_{2} \mathrm{HPO}_{4} .2 \mathrm{H}_{2} 0 ; 0.75 \mathrm{~g} \mathrm{KCl} ; 0.246 \mathrm{~g} \mathrm{MgSO}_{4} .7 \mathrm{H}_{2} 0$ in $1 \mathrm{~L}$ deionised water)) was then added to each well, and the plate incubated $\left(37^{\circ} \mathrm{C}, 1 \mathrm{~h}\right.$; Ikemoto Scientific Technology Co, Tokyo, Japan). Thereafter, a light emission accelerator solution (50 $\mu \mathrm{L}$; Aurora Accelerator, MP Biomedicals Inc., CA, USA) was added to each well, and the chemiluminescence produced by released $\beta$-galactosidase measured with a 96-well plate luminometer (Luminescencer-JNR AB-2100, ATTO 
Bioinstruments, Tokyo, Japan). Agonist activity was recorded as the EC $\times 10$ (defined as the concentration of test solution producing a chemiluminescent signal 10 times that of the blank (negative) control). Two positive controls were used, namely dihydrotesosterone and 11-keto-testosterone (Wako Pure Chemical Industries Ltd, Osaka, Japan). A solvent (vehicle) control (DMSO, Nakalai Tesque Co., Kyoto, Japan) was also used.

\subsection{Sample preparation and extraction: ELISA}

Prior to filtration, $5 \mathrm{~mL}$ of an acetic acid : water: methanol (1:9:90) buffer solution was added to the sample $(500 \mathrm{~mL})$ to ensure an acid $\mathrm{pH}$. Samples were then filtered with GF/C filters (Whatman International Ltd, UK) to remove particulate matter. The sample was then passed through a C18 SPE column (Discovery DSC-18, $6 \mathrm{~mL} 500 \mathrm{mg}$, Supelco, PA USA), which had previously been conditioned with sequential washes of methanol $(6 \mathrm{~mL})$, and deionised water $(6 \mathrm{~mL})$. Thereafter, the columns were immediately washed with deionised water $(50 \mathrm{~mL})$, and eluted with methanol $(5 \mathrm{~mL})$ into a screw cap glass tube (Iwaki borosilicate glass; Asahi Techno Glass, Tokyo), and the resulting solution evaporated to dryness with nitrogen.

Each sample was subjected to a crude fractionation process to isolate fractions containing non-polar chemicals (e.g. many of the persistent organic pollutants), the steroid hormones, and polar compounds. In short, the sample was resuspended in a mixture of 3:1 hexane : dichloromethane $(1 \mathrm{~mL})$, and then loaded onto a florisil column (Strata FL-PR Florisil, $500 \mathrm{mg}, 3 \mathrm{~mL}$; Phenomenex, USA) which had previously been conditioned with hexane $(2.5 \mathrm{~mL})$. After loading of the sample onto the column, the column was washed twice with a mixture of 3:1 hexane: dichloromethane $(2.5 \mathrm{~mL})$. The sample solution passing through the florisil cartridge at this time (the $\mathrm{W}$ fraction) was discarded. Thereafter, the cartridge was washed with a mixture of 1:9 acetone : dichloromethane $(2 \times 2.5$ $\mathrm{mL})$. The collected washes were combined and designated the FL fraction. The FL fraction was evaporated to dryness under nitrogen, re-suspended with $10 \mu \mathrm{L}$ DMSO, $100 \mu \mathrm{L}$ methanol and $890 \mu \mathrm{L}$ of water, and frozen $\left(-20^{\circ} \mathrm{C}\right)$ until subjected to ELISA measurements for testosterone and androstenedione

\subsubsection{Measurement of testosterone}

Measurement of testosterone was conducted using a commercial ELISA kit, namely, "Testosterone ELISA. Enzyme-linked immunosorbent assay for the invitro-diagnostic quantitative determination of testosterone in human serum and plasma" (IBL, Hamburg, Germany) (IBL).

Measurement of hormone was conducted in accordance with the manufacturer's instructions, using standards and reagents supplied in the kit. In short, standards, controls, and samples $(25 \mu \mathrm{L}$ of each; all duplicated) were dispensed individually into wells in the 96-well microplate supplied with the kit. An enzyme conjugate $(200 \mu \mathrm{L})$ was then added to each well. After mixing for $10 \mathrm{~s}$, the plate was incubated uncovered for one hour at room temperature. Thereafter, each well of the plate was washed three times with diluted wash solution $(400 \mu \mathrm{L})$ using a microplate washer (ATLANTIS Microplate Washer, 
ASYS Hitech GmbH, Salzburg, Austria). Substrate solution $(200 \mu \mathrm{L})$ was then added to each well, and the plate incubated for 15 minutes at room temperature. The enzymatic reaction was then stopped by adding stop solution $(100 \mu \mathrm{L})$, and the absorbance at $450 \mathrm{~nm}$ in each well read by a microplate reader (UVM 340 Microplate Reader, ASYS Hitech GmbH, Salzburg, Austria) within 10 minutes of adding the stop solution.

\subsubsection{Measurement of androstenedione}

Measurement of androstenedione was conducted using a commercial ELISA kit, namely, "Androstenedione ELISA. Enzyme-linked immunosorbent assay for the in-vitro-diagnostic quantitative determination of androstenedione in human serum and plasma" (IBL, Hamburg, Germany) (IBL).

Measurement of hormone was conducted in accordance with the manufacturer's instructions, using standards and reagents supplied in the kit. In short, standards, controls, and samples ( $20 \mu \mathrm{L}$ of each; all duplicated) were dispensed individually into wells in the 96-well microplate supplied with the kit. An enzyme conjugate $(200 \mu \mathrm{L})$ was then added to each well. After mixing for $10 \mathrm{~s}$, the plate was incubated uncovered for one hour at room temperature. Thereafter, each well of the plate was washed three times with diluted wash solution $(400 \mu \mathrm{L})$ using a microplate washer (ATLANTIS Microplate Washer, ASYS Hitech GmbH, Salzburg, Austria). Substrate solution $(200 \mu \mathrm{L})$ was then added to each well, and the plate incubated for 15 minutes at room temperature. The enzymatic reaction was then stopped by adding stop solution $(100 \mu \mathrm{L})$, and the absorbance at $450 \mathrm{~nm}$ in each well read by a microplate reader (UVM 340 Microplate Reader, ASYS Hitech $\mathrm{GmbH}$, Salzburg, Austria) within 10 minutes of adding the stop solution.

\subsubsection{Calculation of ELISA results}

The average absorbance values for each set of standards, controls and samples were calculated, and a calibration curve constructed by plotting the mean absorbance obtained from each standard against its concentration, using an automated method utilising 4 parameter logistics. The hormone concentration of samples was determined automatically from the calibration curves. Where samples had concentrations higher than that of the highest standard, the samples were diluted further and the concentration determined again. Sample dilution factors were taken into account when calculating hormone concentrations in the WWTP effluent.

\subsubsection{QA/QC for ELISA}

In order to verify the accuracy and precision of ELISA measurements a number of quality control and assurance procedures were undertaken. For instance, to verify calibration accuracy, check standards (i.e. standards from the kit run as samples) were run in duplicate on each ELISA plate during each ELISA test. In this case, the ratio of nominal concentrations and result values were $83 \%(n=6$, $47-104 \%)$ for androstenedione, and $87 \%(n=7,72-109 \%)$ for testosterone.

To verify that the hormones in samples were passing through the sample preparation process quantitatively, and to verify that the hormones were found in the expected fractions, a number of recovery experiments were undertaken. In the 
first recovery trials, aliquots of kit standards were spiked into deionised water (500 $\mathrm{mL}$ ) at three concentrations (testosterone, 0.3, 1.6, 3.2 $\mathrm{ng} / \mathrm{L}$; and androstenedione, $1.0,5.0,10.0 \mathrm{ng} / \mathrm{L}$, respectively) on three separate occasions, and the samples thereafter processed as per WWTP effluents. The ratio of nominal concentrations and result values (i.e. recovery) were: testosterone, $197 \%(\mathrm{CV}, 21 \% ; 0.3 \mathrm{ng} / \mathrm{L}$, $243 \% ; 1.6 \mathrm{ng} / \mathrm{L}, 164 \% ; 3.2 \mathrm{ng} / \mathrm{L}, 184 \%$ ), and androstenedione, $280 \%$ (CV, 18\%; $1.0 \mathrm{ng} / \mathrm{L}, 322 \% ; 5.0 \mathrm{ng} / \mathrm{L}, 292 \% 10.0 \mathrm{ng} / \mathrm{L}, 224 \%)$. The second recovery trial examined the behaviour of our target hormones in a composite WWTP effluent (prepared by blending equal volumes of five WWTP effluents of the lowest hormonal activity and measured hormone concentrations). The hormone concentrations in the composite sample (i.e. background levels) were both estimated from previous measurements and directly measured $(n=2)$; testosterone: estimated, $0.2 \mathrm{ng} / \mathrm{L}$; measured, $1.1 \mathrm{ng} / \mathrm{L}$; androstenedione: estimated, $0.0 \mathrm{ng} / \mathrm{L}$; measured, $1.4 \mathrm{ng} / \mathrm{L}$. Aliquots of kit standards were spiked into the composite WWTP effluent $(500 \mathrm{~mL})$, and the samples thereafter processed as per WWTP effluents. Nominal concentrations (corrected for background hormone concentrations) were testosterone, $2.7 \mathrm{ng} / \mathrm{L}$, and androstenedione, $2.9 \mathrm{ng} / \mathrm{L}$. Measured concentrations were testosterone, $4.4 \mathrm{ng} / \mathrm{L}$, and androstenedione, 6.9 ng/L. Recoveries were testosterone, 162\%; and androstenedione, 238\%. Although higher than desirable, the recoveries for testosterone and androstendione were deemed acceptable due to the relatively low variation in the data.

In discussing hormone concentrations, data has not been corrected for plate response to check standards or for methodological recovery.

\subsection{Statistical analysis}

For statistical comparison, where the data did not conform to the stringent assumptions of parametric statistical methodologies, non-parametric statistical methodologies were used instead. For instance, the non-parametric analogue to the one way ANOVA (the Kruscal-Wallis analysis of variance), was used to assess for statistically significant differences in distributions within independent measures with more than two groups. If differences were detected, the MannWhitney test (the non-parametric equivalent of the t-test), was used for any subsequent post-hoc comparisons, or where a difference in the distributions in only two groups was investigated. Statistical analysis was conducted using SPSS version 14.0 for windows (SPSS Inc, Chicago) and XLStatistics Ver 5.0.

\section{Results and discussion}

In total, there are $\sim 185$ WWTPs in Victoria (not including plants under construction, in process of being decommissioned, and those for which no information was available). Of these, $56 \%$ are in the north of the state (defined as being north of the Great Dividing Range), and 44\% in the south. By treatment type, $124(67 \%)$ are lagoon based plants, including those reporting treatment using maturation lagoons, facultative lagoons, oxidation ponds. Of these lagoonbased plants, two-thirds are in the north of the state. The remaining 61 WWTPs $(33 \%)$ are mechanical treatment plants, including those using various forms of 
activated sludge processes, extended aeration/flocculation technology, and trickle filters. Of these mechanical plants, two-thirds are in the south of the state.

In the Winter 2006 survey, no sample produced a response in the androgen assay (hAR assay). The results of a concurrent toxicity assay (data not presented) suggest that a lack of assay response was related to lack of androgenic compounds, rather than the direct toxic effect of the effluent, since most samples were non-toxic or weakly-toxic. In other words, lack of response by the hAR assay was not caused by the samples killing off the yeast, but rather suggested that either (a) androgenic activity was too low for the bioassay, and/or (b) the compounds are in fractions not studied. That the lack of androgenic response is due to lack of androgens in the sample is in part assured because we measured androgenic activity in all three fractions (W, FL and RM), and found no activity in any fraction; and in part assured because the nature of the testing itself, i.e. the use of positive controls in the assay. In this case, the assay responded normally to the two positive controls used, namely dihydrotestosterone and 11-ketotestosterone. That the sample preparation process does not remove steroid hormones from the sample was in part assured through early QA/QC procedures in which the hormones were tracked through the separation steps (data not presented), and thereafter the use of spiked composite WWTP effluent to assess analyte recovery. In this latter case, testosterone and androstenedione were quantitatively recovered in the FL fraction, and, if anything, the ELISA system overestimates testosterone and androstenedione concentrations. Because none of the Winter 2006 samples produced a response in the hAR assay, this test was not conducted on Summer 2007 samples.

Measurement of testosterone and androstenedione concentrations by ELISA suggests that there were indeed androgens present in both the Winter 2006 and Summer 2007 samples, but at concentrations generally below $3 \mathrm{ng} / \mathrm{L}$ testosterone (Winter mean concentration $0.93 \mathrm{ng} / \mathrm{L}$ (range $<\mathrm{LOD}-2.85 \mathrm{ng} / \mathrm{L}$ ); Summer mean concentration $0.92 \mathrm{ng} / \mathrm{L}$ (range $<\mathrm{LOD}-2.90 \mathrm{ng} / \mathrm{L}$ ); Figure 1) and below 10 $\mathrm{ng} / \mathrm{L}$ androstenedione (Winter mean concentration $2.65 \mathrm{ng} / \mathrm{L}$ (range $<\mathrm{LOD}-$ $9.30 \mathrm{ng} / \mathrm{L}$ ); Summer mean concentration $2.39 \mathrm{ng} / \mathrm{L}$ (range < LOD - $14.65 \mathrm{ng} / \mathrm{L}$ ); Figure 2). There were no statistical differences in the concentration of either testosterone or androstenedione within (i.e. north or south of state) or between treatments in either Winter 2006 or Summer 2007 surveys, and no statistical differences in the concentration of either androgen between Winter 2006 and Summer 2007.

The low levels of testosterone observed in our study are consistent with Fernandez et al. [6] and Esperanza et al. [7], neither of whom reported measurable amounts of testosterone in their surveys of Canadian and Spanish WWTPs, respectively. The low levels of testosterone and androstenedione observed in our study are also broadly consistent with recent reports by Tan et al. [4] of low ng/L concentrations of androsterone and etiocholanolone (metabolites of testosterone and androstenedione, respectively) in the effluent from five WWTPs in South East Queensland employing activated sludge as the secondary biological treatment step $(<\mathrm{BDL}-\sim 26 \mathrm{ng} / \mathrm{L})$. The rationale for choosing to monitor androsterone and etiocholanolone concentrations rather than testosterone 

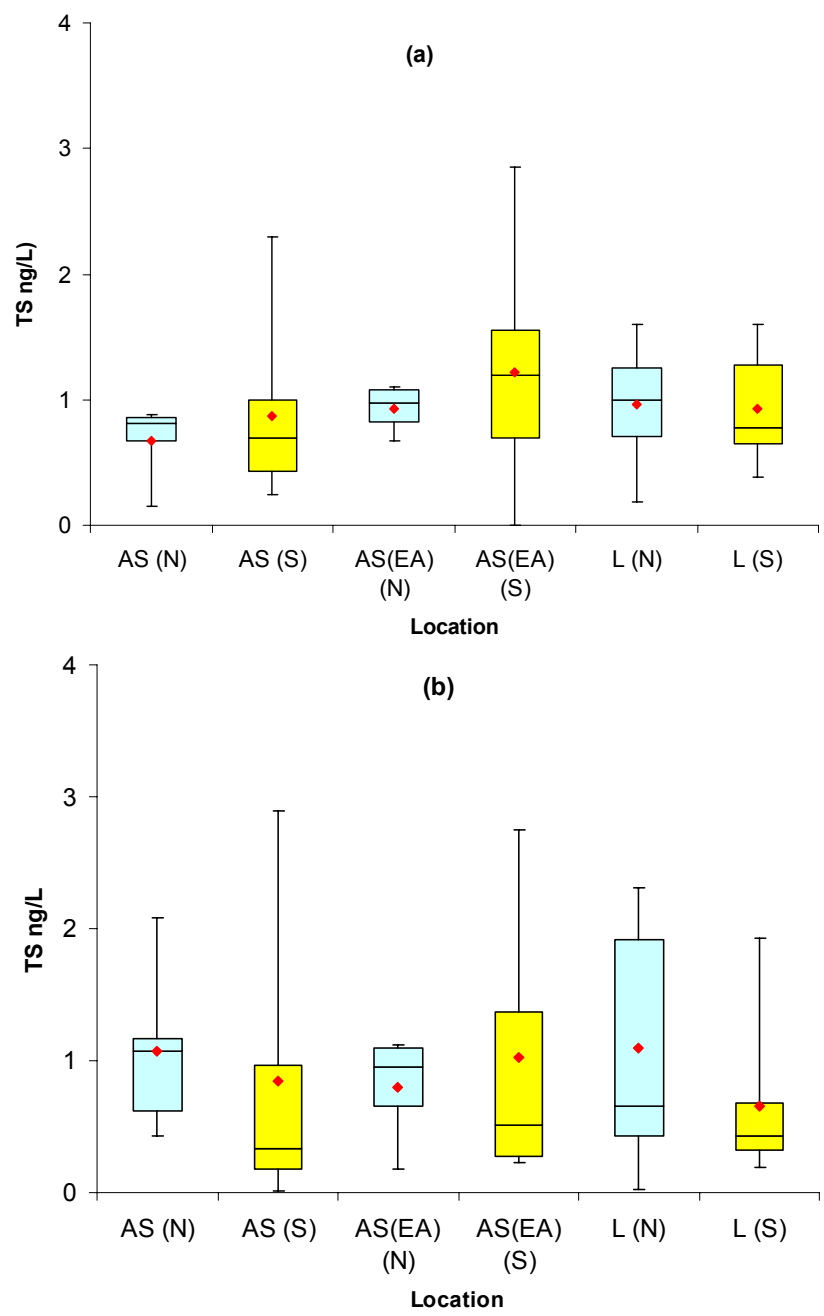

Figure 1: $\quad$ Summary of testosterone concentrations in Winter 2006 (a) and Summer 2007 (b) samples. AS, activated sludge-based WWTP; AS(EA), treatment based on extended aeration-flocculation; L, lagoon-based WWTP; N, north; S, south; •, arithmetic mean; line within data boxes, data median; upper and lower boundaries of boxes, 75 th and 25 th percentile of data.

and androstenedione is not explored by Tan et al. [4], but it is perhaps not unreasonable to assume that low levels of these major metabolites in the effluents would have translated into low levels of parent compound in the effluents. 

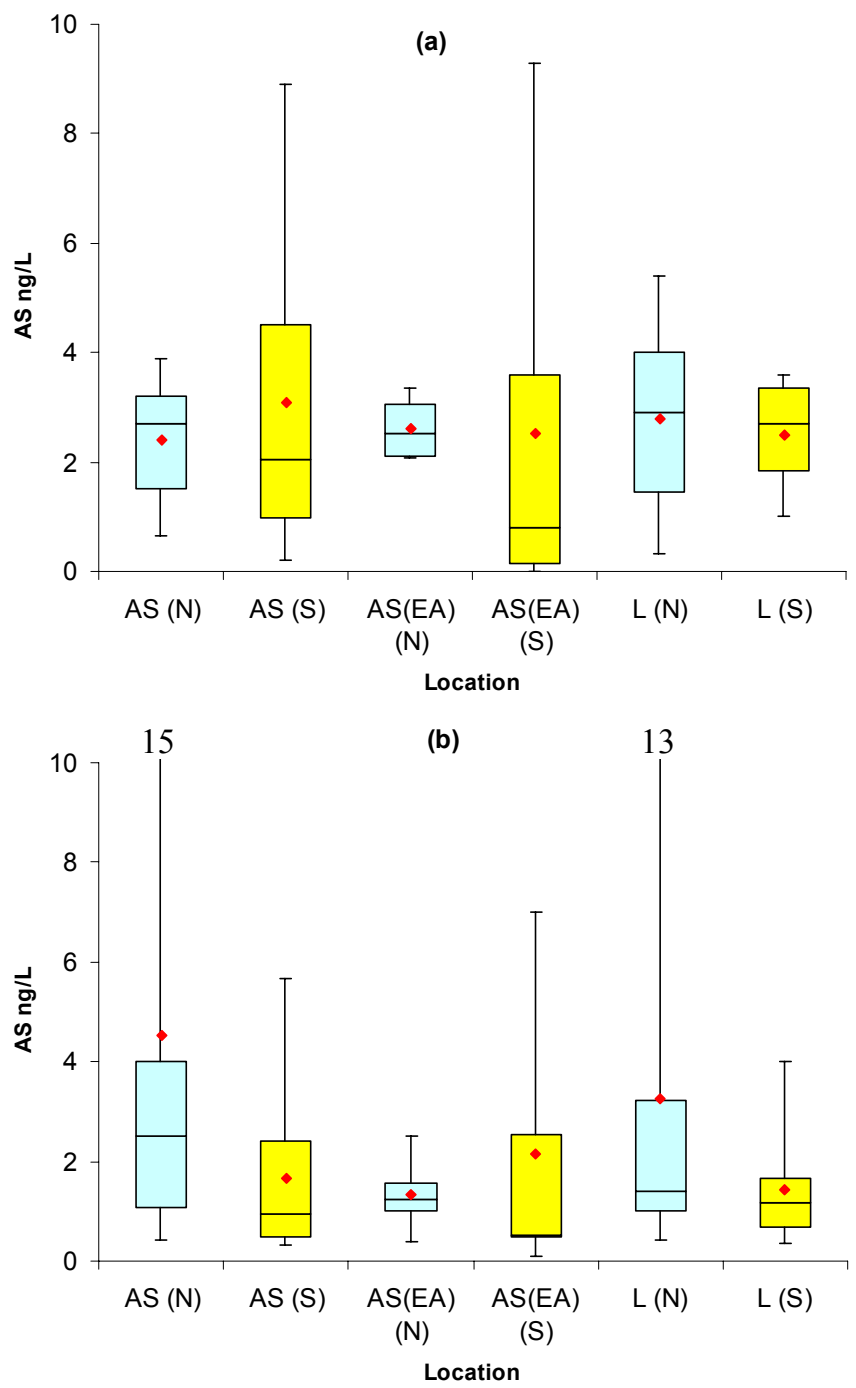

Figure 2: $\quad$ Summary of androstenedione concentrations in Winter 2006 (a) and Summer 2007 (b) samples. AS, activated sludge-based WWTP; AS(EA), treatment based on extended aerationflocculation; L, lagoon-based WWTP; N, north; S, south; arithmetic mean; line within data boxes, data median; upper and lower boundaries of boxes, 75 th and 25 th percentile of data.

The lack of androgenic activity and the low levels of testosterone and androstenedione observed in our study is, however, at odds with reports by Leusch et al. [8] of high, and highly variable, levels of androgenic activity in the final effluents of thirteen WWTPs in southern Queensland (12 suspended 
film/activated sludge plants, 1 trickle filter-based plant) and two WWTPs in Canterbury, New Zealand (one trickle filter-based plant, and one oxidation pond treatment system) $(<6.5-736 \mathrm{ng} / \mathrm{L}$ testosterone equivalents). Chapman et al. [3] claim these levels are similar to those reported for WWTPs in the United Kingdom $(<113-4000 \mathrm{ng} / \mathrm{L}$ DHT equivalents in a yeast assay, 5 and 34-635 ng/L (DHT equivalents in a yeast assay) [9]. However, Kirk et al. [10] actually report that androgenic activity was below their $\mathrm{MDL}(<113 \mathrm{ng} / \mathrm{L}$ DHT equiv.) in all bar one effluent, and the high levels of androgenic activity reported by Thomas et al. [9] were for effluents receiving only primary treatment (cf. the suspended growth/activated sludge plants in Leusch et al.'s [8] 2006 survey). Androgenic activity in the effluent from the activated sludge plants in Thomas et al's survey were $<23 \mathrm{ng} / \mathrm{L}$ DHT equiv. [9]

We must, however, be very careful not to make too much of these comparisons for a number of reasons, namely (1) the different target analytes and experimental protocols of the studies, including those associated with sample handling and preparation, and the different methods used to determine androgenic activity and hormone concentrations, and (2) that, nationally and internationally very little is known of androgenic activity and the levels of specific androgens in WWTP discharges (particularly compared to our knowledge of estrogens). In short, given the paucity of information available, nationally or internationally, any discrepancies between Victorian values and those in southern Queensland may simply reflect reality, i.e. that there is significant variation in androgenic activity and the concentration of specific androgens in WWTP effluents.

\section{Conclusions}

This study has shown that there are low levels (typically $<10 \mathrm{ng} / \mathrm{L}$ ) of testosterone and androstenedione in the discharges of Victorian WWTPs. Given both the biological activity of these materials, and the paucity of environmental information, more research is warranted to verify the androgenic activity and specific hormone/metabolite levels reported in these studies. Moreover, given that little is known about the effect of exposure of fish and other aquatic organisms to androgenic chemicals originating from WWTPs, to determine if the androgenic activity reported in this and other recent Australian studies is sufficient to induce a physiological effect in exposed aquatic organisms, especially Australian native fish.

\section{Acknowledgements}

The project team would like to acknowledge the financial support provided by the Victorian Water Trust (Project \# 33V-4000) and Department of Primary Industries Victoria, Australia (Project \# 08271 and 08280), and gives its thanks to all the water authorities in Victoria, who, in one way or another, contributed to the success of this project. 


\section{References}

[1] Colborn, T., Dumanoski, D. \& Myers, J.P., Our Stolen Future. Dutton Press, New York, 1996.

[2] Damstra, T., Barlow, S., Bergman, A., Kavlock, R. \& Van Der Kraak, G., (eds). Global assessment of the state-of-the-science of endocrine disruptors. World Health Organisation / International Program on Chemical Safety, 2002. Available on-line: www.who.int/ipcs/publications/new_issues/ endocrine_disruptors/en/index.html

[3] CRC Water Quality \& Treatment Occasional Paper 8: Chemicals of concern in wastewater treatment plant effluent: State of the science in Australia. CRC for Water Quality and Treatment, Salisbury, Australia, 2007.

[4] Tan, B.L.L., Hawker, D.W., Müller, J.F., Leusch, F.D.L., Tremblay, L.A. \& Chapman, H.F., Comprehensive study of endocrine disrupting compounds using grab and passive sampling at selected wastewater treatment plants in South East Queensland, Australia. Environment International 33, pp 654-669, 2007.

[5] Shiraishi, F., Shiraishi, H., Nishikawa, J., Nishihara, T. \& Morita, M., Development of a simple operational estrogenicity assay system using the Yeast Two-Hybrid System. Journal of Environmental Chemistry 10, pp 5764, 2000.

[6] Fernandez, M.P., Ikonomou, M.G. \& Buchanan, I., An assessment of estrogenic organic contaminants in Canadian wastewaters. Science of the Total Environment 373, pp 250-269, 2007.

[7] Esperanza, M., Suidan, M.T., Marfil-Vega, R., Gonzalez, C., Sorial, G.A., McCauley, P. \& Brenner, R., Fate of sex hormones in two pilot-scale municipal wastewater treatment plants: Conventional treatment. Chemosphere 66, pp 1535-1544, 2007.

[8] Leusch, F.D.L., Chapman, H., van der Heuvel, M.R., Tan, B.L.L., Gooneratne, S.R. \& Tremblay, L.A., Bioassay-derived androgenic and estrogenic activity in municipal sewage in Australia and New Zealand. Ecotoxicology and Environmental Safety 65, pp 403-411, 2006.

[9] Thomas, K.V., Hurst, M.R., Matthiessen, P., McHugh, M., Smith, A. \& Waldock, M.J., An assessment of in vitro androgenic activity and the identification of environmental androgens in United Kingdom estuaries. Environmental Toxicology and Chemistry 21, pp 1456-1461, 2002.

[10] Kirk, L.A., Tyler, C.R., Lye, C.M. \& Sumpter, J.P., Changes in estrogenic and androgenic activities at different stages of treatment in wastewater treatment works. Environmental Toxicology and Chemistry 21, pp 972 979, 2002. 